Research article

\title{
Variability in yield and composition of oil from Indian Sandalwood (Santalum album L.) trees grown in homogeneous conditions
}

\author{
Surendra Singh Bisht*, Mamata Ravindra and Divyashree N Gayathri \\ Chemistry and Bio-Prospecting Division, Institute of Wood Science and Technology, \\ $18^{\text {th }}$ Cross Malleshwaram, Bangalore-560003, Karnataka, India \\ *Corresponding Author: ssbchem@gmail.com \\ [Accepted: 20 February 2019]
}

\begin{abstract}
The study evaluated the variability in yield and composition of oil from the heartwood of Indian Sandalwood (Santalum album) trees grown in homogeneous condition. Trees grown at Institute of Wood Science and Technology campus, Bengaluru were considered in this study. Wood samples were collected from trees having different girth size (47.1, 53.4, 61.2, 69.1, 72.2, $74,75.4,81.6$ and $82.4 \mathrm{~cm}$ ). About $500 \mathrm{~g}$ of heartwood powder per sample was extracted by hydro-distillation method using Clevenger's apparatus. Oil yield extracted from these samples varied from 1.6-3.6\% of heartwood. Chemical profiling of the oil samples was carried out by gas chromatography-mass spectrometry (GC-MS-QP-2010 Ultra Auto Sampler). A chemically diversified alkanes, sesquiterpenoids, sesquiterpene, fatty acids, and alcohols, were detected. The major constituents were $\alpha$-santalol (41.7-53.67\%), $\beta$-santalol (18.2-27.9\%), epi- $\beta$-santalol (2.7$7.18 \%$ ), $\beta$-santalene (1.39-5.30\%), $\alpha$-santalene (0.4-4.87\%), and $\alpha$-bergamotol (3.1-9.3\%). In this study, it was concluded that the oil yield and its composition varies among the trees with different girth. But no particular trends were observed between the girth size and oil yield.
\end{abstract}

Keywords: Santalum album L. - Indian Sandalwood oil - Composition - Girth - GC-MS.

[Cite as: Bisht SS, Ravindra M \& Gayathri DN (2019) Variability in yield and composition of oil from Indian Sandalwood (Santalum album L.) trees grown in homogeneous conditions. Tropical Plant Research 6(1): 3136]

\section{INTRODUCTION}

Santalum album L. is a small to medium-sized, evergreen semi parasitic tree of family Santalaceae (Fox 2000, Chaudhary et al. 2016). S. album commonly known as Indian Sandalwood is one of the oldest and precious sources of natural fragrance with immense medicinal and commercial significance (Burdock \& Carabin 2008, Hansda 2009, Bajpai et al. 2016). Sandalwood has been esteemed all over the world for its peculiar, sweet, long lasting and medicinally valued fragrant oil. Indian Sandalwood oil derived from heartwood of the tree have been used in various traditional systems of medicine, like Ayurveda, Siddha and Unani medicine in the treatment and prevention of wide range of ailments (Sensarma 1989). The value of Indian Sandalwood tree mainly depends on the volume of its heartwood and the quantity and quality of the heartwood oil. The quality of SW oil mainly because of the concentration of oxygenated sesquiterpenes i.e. $\alpha$-santalol and $\beta$-santalol, due to which it has a pleasant characteristic aroma. Earlier reported main sesquiterpene and sesquiterpene alcohols of Indian Sandalwood (Santalum album L.) oil were $\alpha$-santalol (1), $\beta$-santalol (2), $\alpha$-bergamotol (3), epi-cis- $\beta$ santalol (4), cis-lanceol (5) and $\alpha$-bisabolol (6) (Fig. 1). The hydrocarbons, $\alpha$-santalene (7), $\beta$-santalene (8), epi$\beta$-santalene (9), $\alpha$-bergamotene (10), $\beta$-bisabolene (11) and $\alpha$-curcumene (12) were also present in the oil (Fig. 1) (Verghese et al. 1990).

Various studies have been carried out for documenting variation in oil content and its composition. The study conducted on heartwood oil yield in Santalum yasi Seem and S. album by Doran et al. (2005) and Xiaojin et al. (2011). The variation of oil content in 6 year old $S$. album was estimated from $0.64 \%$ to $1.78 \%$. The studies carried out in Sri Lanka by Subasinghe et al. (2013) on S. album showed a higher variation of oil content and they found high oil content, i.e. up to $6.36 \%$. Further, the research was conducted on the estimation of alpha and beta santalol levels in S. album, Santalum spicatum, S. yasi, Santalum austrocaledonicum by some other 
researcher as well (Brand et al. 2006, 2007, Xiaojin et al. 2011). Moreover, the content and composition of oil from the central and transition zones of the Sandalwood disc (Shankaranarayana et al. 1998), analysis of growth and oil composition (Xiaojin et al. 2011) and solvent extractable volatile profiling (Misra et al. 2013) from heartwood of East Indian sandalwood tree are the few studies in this direction.

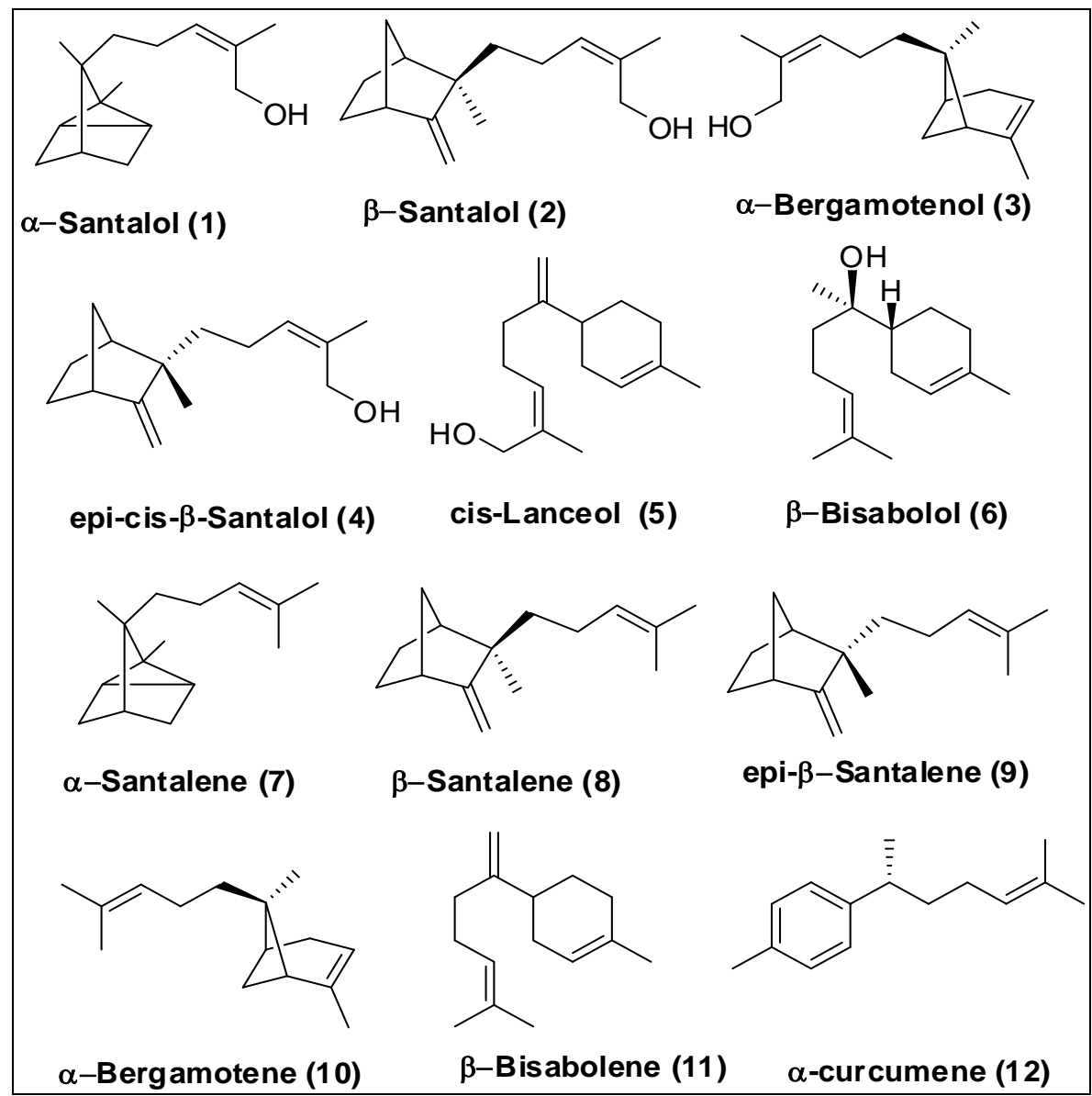

Figure 1. The volatile compounds reported from Indian sandalwood oil.

It has been found that in most of these studies the growing conditions or environments were not similar. Moreover, the quantities of the heartwood for extracting oil were not sufficient, which also plays an important role in estimating oil yield and its composition. Variations in the composition of oil from trees grown in homogenous condition may have an effect on the quality of SW oil, which could lead to inconsistency in medicinal and aromatherapy properties. In this connection, it is imperative to understand and estimate the yield and chemical composition of Sandalwood oil from mature Sandalwood tree grown in homogenous conditions. Therefore, the aim of this study was to analyze the variation in yield and composition of oil from Sandalwood trees grown in uniform condition.

\section{MATERIALS AND METHODS}

General experimental methods

Heartwoods were collected from Sandalwood trees grown in Institute of Wood Science and Technology campus. SW oil was extracted by hydro-distillation method using Cleavenger's apparatus. Refractive index was measured by Abbe 5 Refractometer. Relative density was measured gravimetric method using glass specific gravity bottle. The instrument Buchi Rota Vapor used for evaporation of excess amount solvents. The resulting extracted oils were analyzed by GC-MS (GCMS-QP 2010 Plus, Shimadzu make).

\section{Plant materials and chemicals}

SW samples were collected from different girth size sandalwood trees growing in the campus of Institute of Wood Science and Technology, Bengaluru, India. Collected wood samples were processed for separation and chipping of heartwood by chopping method. Heartwood chips were pulverized into powders and air dried for 24 $\mathrm{h}$, prior to hydrodistillation. The LR and HPLC grade solvents (n-hexane, chloroform, diethyl ether etc) were purchased from Merck Specialties Pvt. Ltd. and HiMediaLaboratories Pvt. Ltd. Distilled water was used during the experiment. 
Extraction of SW oil

Total $500 \mathrm{~g}$ of heartwood powder was hydro distillated for 14-15 hr by using Clevenger's apparatus (Hettiarachchi 2008). The hydrodisttiled oil was separated from water by separating funnel using organic solvent (petroleum ether). Collected oil and solvent mixture was dried over $\mathrm{Na}_{2} \mathrm{SO}_{4}$ and concentrated under reduced pressure using rotovapor at $35-40{ }^{\circ} \mathrm{C}$ to get oily fractions. The resulting oily mass was subjected to GCMS analysis (Bisht \& Hemanthraj 2014).

Physicochemical analysis

Refractive index was recorded by Abbe 5 Refractometer at room temperature. Relative density was calculated by the ratio of the mass of a given volume of the oil to the mass of an equal volume of distilled water at room temperature.

The relative density was calculated by the following equation:

$$
\text { Relative Density }=\mathrm{m}_{2}-\mathrm{m}_{\mathrm{o}} / \mathrm{m}_{1}-\mathrm{m}_{0}
$$

Where,

- $\mathrm{m}_{0}$ was the mass in grams of the empty specific gravity bottle,

- $\mathrm{m}_{1}$ the mass in grams of the specific gravity bottle filled with water,

- $\mathrm{m}_{2}$ is the mass, in grams, of the specific gravity bottle filled with the essential oil.

Equal volumes of the essential oil and water were weighed successively in a glass specific gravity bottle at room temperature.

\section{GC-MS analysis}

The resulting oily masses were analyzed by GC-MS, equipped with RTX-Wax capillary column, connected to anion trap quadrupole (ITQ) mass selective detector, with a unit mass resolution. The split was 1:90, with helium as the carrier gas at a flow rate of $1 \mathrm{ml} / \mathrm{min}$, while the damping gas flow was $0.3 \mathrm{ml} \mathrm{min}^{-1}$. The GC oven temperature program was as follows: $40^{\circ} \mathrm{C}$ to $300^{\circ} \mathrm{C}$., by ramping at $3^{\circ} \mathrm{C}$, and held at $220^{\circ} \mathrm{C}$ for 20 min. The injector temperature was maintained at $220^{\circ} \mathrm{C}$ and the transfer line was held at $220^{\circ} \mathrm{C}$. The detection was performed by a Thermo ITQ 900 mass spectrometer in the EI mode (ionization energy of $70 \mathrm{eV}$, ion source temperature of $180^{\circ} \mathrm{C}$, emission current of $220 \mathrm{~mA}$ ). The acquisition was made in full scanning mode (mass range 50-900 $\mathrm{m} \mathrm{z}^{-1} ; 3 \mathrm{scans} \mathrm{s}^{-1}$ ). Maximum ionization time was $25 \mathrm{~ms}$. A solvent delay time of $5 \mathrm{~min}$ (setoff) was used to avoid overloading the mass spectrometer with solvent. The resulting GC-MS profile was analyzed using National Institute of Standards and Technology (NIST-2011, Washington DC, USA) and Dr. Duke's Phytochemical and Ethnobotanical Database (http://www.ars-grin.gov/duke/). Qualitative analysis of metabolite was done using its percentage peak area appeared at the total ion chromatogram in GC-MS analysis (Bisht \& Hemanthraj 2014).

\section{RESULTS AND DISCUSSION}

Wood samples were collected from trees having different girth size i.e., 47.1, 53.4, 61.2, 69.1, 72.2, 74, 75.4, 81.6 and $82.4 \mathrm{~cm}$. Oil yield from these samples varied from 1.6 to $3.6 \%$ of heartwood (Table 1). Highest \% yield of oil (3.6\%) was observed in tree with girth $72.2 \mathrm{~cm}$ while the lowest $\%$ oil yield i.e. 1.7 and $1.6 \%$ in tree with girth size $69.1 \mathrm{~cm}$ and 72.2 respectively. The values of physical parameters such as relative density and specific gravity of the oils were observed within the limit of high-quality SW oil (ISO 2002). The colour were observed as colourless to pale yellow and refractive index (1.501-1.5025) of the oil were almost consistent with the all samples while specific gravity was varies from 0.9435-0.974 (Table 1).

Table 1. Oil yield and physical parameter of extracted SW oil. [ \pm standard error]

\begin{tabular}{lrrrrr}
\hline Sample & $\begin{array}{r}\text { Girth size } \\
(\mathbf{c m})\end{array}$ & Oil yield $(\%)$ & Oil Colour & $\begin{array}{r}\text { Refractive } \\
\text { index }(\mathbf{R I})\end{array}$ & Specific gravity \\
\hline T1 & 47.1 & $2.5 \pm 0.1$ & Colourless & 1.5010 & $0.960( \pm 0.01)$ \\
T2 & 53.4 & $2.0 \pm 0.1$ & Pale yellow & 1.5015 & $0.964( \pm 0.02)$ \\
T3 & 61.2 & $2.2 \pm 0.2$ & Pale yellow & 1.5020 & $0.963( \pm 0.01)$ \\
T4 & 69.1 & $1.7 \pm 0.2$ & Pale yellow & 1.5025 & $0.957( \pm 0.03)$ \\
T5 & 72.2 & $3.6 \pm 0.1$ & Pale yellow & 1.5010 & $0.962( \pm 0.02)$ \\
T6 & 72.2 & $1.6 \pm 0.1$ & Colourless & 1.5020 & $0.942( \pm 0.02)$ \\
T7 & 74.0 & $2.0 \pm 0.2$ & Colourless & 1.5020 & $0.9435( \pm 0.01)$ \\
T8 & 75.4 & $2.0 \pm 0.2$ & Pale yellow & 1.5020 & $0.974( \pm 0.03)$ \\
T9 & 81.6 & $2.6 \pm 0.1$ & Colourless & 1.5010 & $0.953( \pm 0.01)$ \\
T10 & 82.4 & $3.2 \pm 0.2$ & Pale yellow & 1.5025 & $0.963( \pm 0.01)$ \\
\hline
\end{tabular}




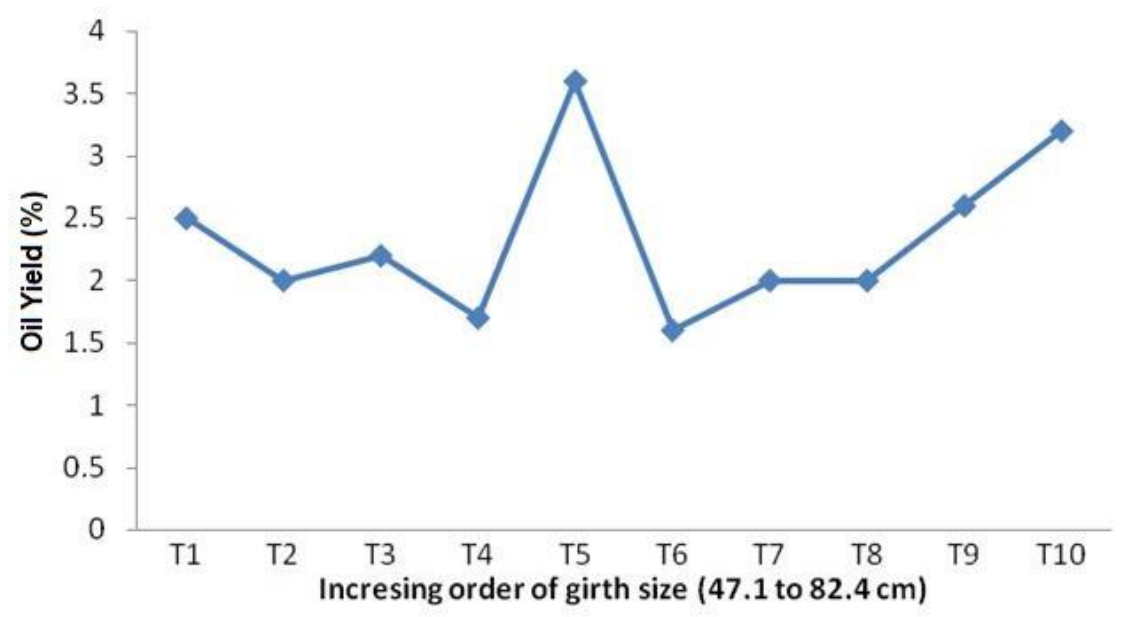

Figure 1. Variation trend of $\% \mathrm{SW}$ oil yield in different girth SW trees.

Total 35 volatile metabolites were detected with significant area percentage in total ion chromatogram (Fig. 2 ). Diversified phytochemicals such as alkanes, sesquiterpenoids, sesquiterpene, fatty acids, and alcohols were observed in extracted Sandalwood oil. The major constituents were $\alpha$-santalol (41.7-53.67 \%), $\beta$-santalol (18.2$27.9 \%)$, epi- $\beta$-santalol (2.7-7.18\%), $\beta$-santalene (1.39-5.30\%), $\alpha$-santalene $(0.4-4.87 \%)$, and $\alpha$-bergamotol $(3.1-9.3 \%)$ (Table $2 \& 3)$.

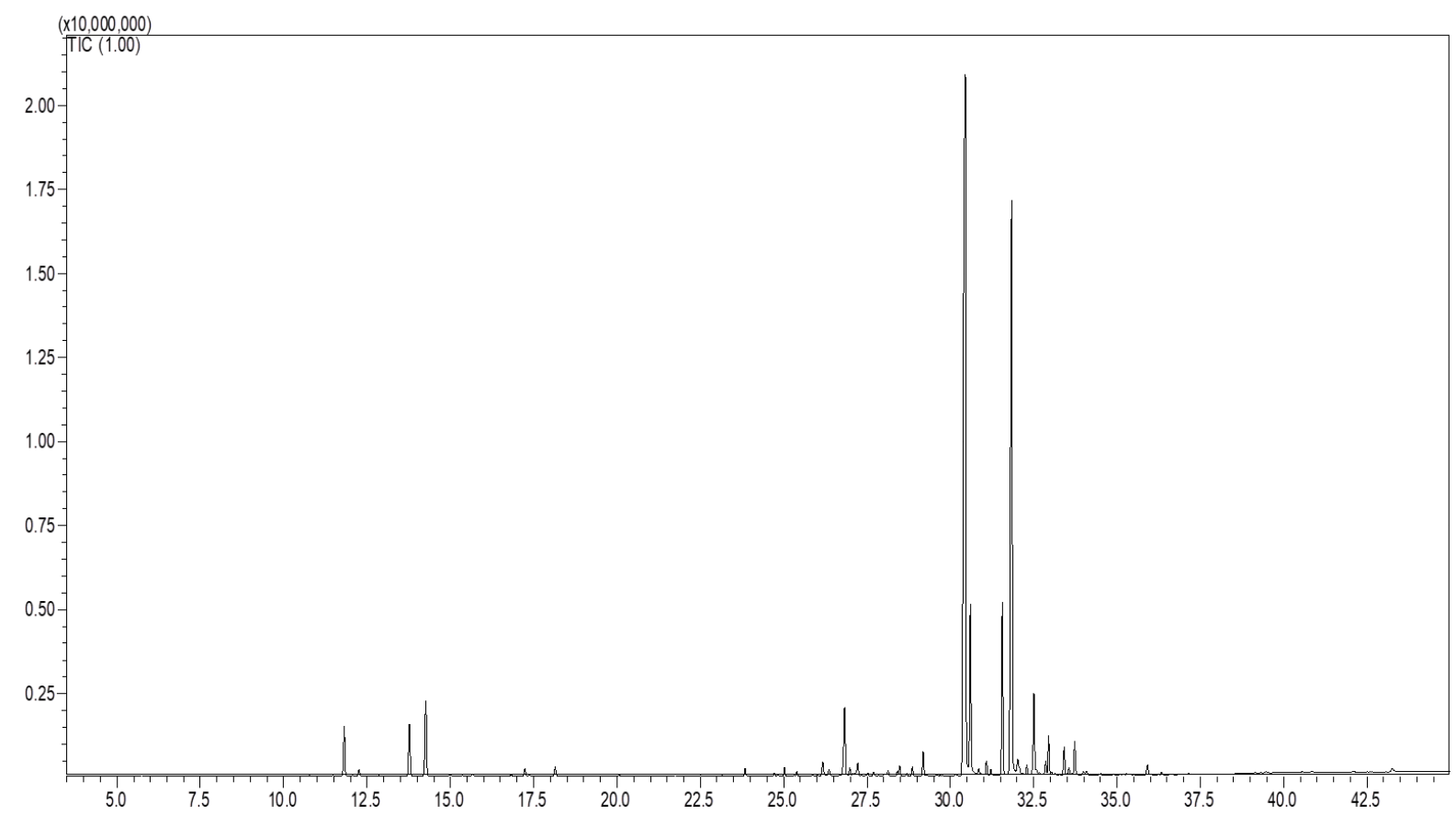

Figure 2. GC-MS Chromatogram of Heartwood Oil.

Table 2. Mass fragmentation of GC-MS identified metabolites.

\begin{tabular}{llrrr}
\hline $\begin{array}{l}\text { tR } \\
(\text { Min) }\end{array}$ & Metabolites & $\begin{array}{r}\text { Molecular } \\
\text { formula }\end{array}$ & Mol. Wt & $\begin{array}{r}\text { Mass fragmentation } \\
\text { (mass m z } \mathbf{~}^{-1} \text { values) }\end{array}$ \\
\hline 11.81 & $\alpha$-Santalene & $\mathrm{C}_{15} \mathrm{H}_{24}$ & 204 & $204(\mathrm{M}+), 189,161,121,107,69,41$ \\
14.26 & $\beta$-Santalene & $\mathrm{C}_{15} \mathrm{H}_{24}$ & 204 & $204(\mathrm{M}+), 122,94,79,67,55,41$ \\
30.44 & $\alpha$-Santalol & $\mathrm{C}_{15} \mathrm{H}_{24} \mathrm{O}$ & 220 & $220(\mathrm{M}+), 187,121,107,93,79,41$ \\
30.6 & Z- $\alpha$-trans-Bergamotol & $\mathrm{C}_{15} \mathrm{H}_{24} \mathrm{O}$ & 220 & $220(\mathrm{M}+), 132,119,107,93,79,41$ \\
31.55 & E-cis-epi- $\beta$-Santalol & $\mathrm{C}_{15} \mathrm{H}_{24} \mathrm{O}$ & 220 & $220(\mathrm{M}+), 122,107,94,79,67,41$ \\
32.50 & trans- $\beta$-Santalol & $\mathrm{C}_{15} \mathrm{H}_{24} \mathrm{O}$ & 220 & $220(\mathrm{M}+), 189,122,94,79,67,41$ \\
\hline
\end{tabular}

The quantity of metabolites varied among all the samples and the metabolites which were detected in area percentage $\geq 0.50$ of total ion chromatogram considered as major metabolites (Fig. 2; Table 2). The results showed that the extracted oils contain high concentration of $\alpha$-santalol and $\beta$-santalol at retention time (tR) $30.44 \mathrm{~min}$ and $32.5 \mathrm{~min}$ respectively. The concentration of $\alpha$-santalol varied from $41.7-53.67 \%$, the lowest being in T-2 and highest in T-3. The content of $\beta$-santalol ranged from 18.2-27.9\%, the lowest being in T-8 and highest in $\mathrm{T}-10$. 
Table 3. Variation of metabolites (area \%) in extracted SW oil.

\begin{tabular}{|c|c|c|c|c|c|c|c|c|c|c|}
\hline \multirow{2}{*}{ Metabolites } & \multicolumn{10}{|c|}{ Area \% } \\
\hline & T1 & $\mathbf{T 2}$ & T3 & T4 & T5 & T6 & T7 & T8 & T9 & T10 \\
\hline$\alpha$-Santalene & 0.6 & 4.8 & 1.3 & 1.2 & 1.0 & 0.3 & 0.9 & 1.1 & 0.4 & 0.8 \\
\hline$\beta$-Santalene & 2 & 4.9 & 3.9 & 3.1 & 2.6 & 1.4 & 2.9 & 3.1 & 1.5 & 2.7 \\
\hline$\alpha$-Santalol & 53.2 & 41.7 & 53.7 & 45.6 & 52.9 & 47.4 & 51.0 & 47.4 & 47.9 & 46.2 \\
\hline Z- $\alpha$-trans-Bergamotol & 6.8 & 6.3 & 5.2 & 8.4 & 6.6 & 7.2 & 6.2 & 4.9 & 9.3 & 7.5 \\
\hline E-cis-epi- $\beta$-Santalol & 3.8 & 4.1 & 2.7 & 4.2 & 3.4 & 4.9 & 3.7 & 2.8 & 5.5 & 5.5 \\
\hline trans- $\beta$-Santalol & 25.0 & 24.1 & 25.9 & 25.1 & 26.8 & 25.2 & 25.8 & 18.2 & 27.0 & 27.9 \\
\hline
\end{tabular}

The six metabolites were present in significant amount in all samples with little variation in concentration of $\alpha$-santalol and $\beta$-santalol. While $\alpha$-santalene, $\beta$-santalene, epi- $\beta$-santalene, $\alpha$-bergamotol and epi- $\beta$-santalol were detected with high deviation. Further the trend in variation of major metabolites among the different girth trees was analyzed. In general the relative variation of the $\alpha$-santalol and $\beta$-santalol among the all samples was almost same (Fig. 3). Although there was no particular relationship observed between the girth sizes and oil yield of Sandalwood trees grown in the same location. There may be a strong influence of genetic characteristics to the quantity and quality of sandalwood oil variations of $S$. album trees of similar size growing under similar soil and climatic conditions.

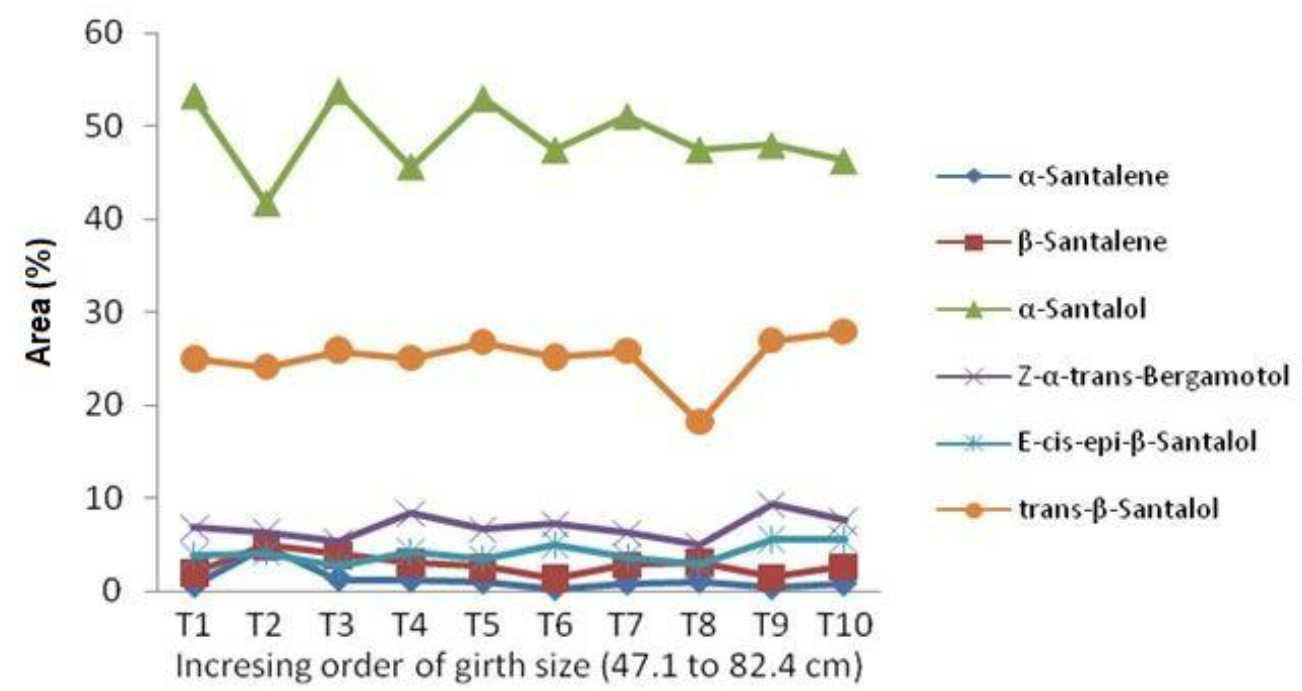

Figure 3. Variation trend of SW oil composition in different girth SW trees.

\section{CONCLUSION}

Metabolite profiling of the heartwood oil by using GC-MS techniques has provided a vast array of metabolites, which included n-alkanes, sesquiterpene, sesquiterpenoids, fatty acids, alcohols and other hydrocarbons. Total $\%$ oil yield from trees having different girth size $(47.1-82.4 \mathrm{~cm})$ were observed from $1.6-$ $3.6 \%$ of heartwood. Although, there were no particular trends observed between the girth sizes and \% oil yield. But in general, almost similar type trends in the relative ratio of $\alpha$-santalol and $\beta$-santalol content were observed. The physical parameters such as relative density and specific gravity of the oils were observed within the limit of high quality SW oil. These variations can be suspected that the genetic factors may play a significant role in oil formation. The unknown causes of the variation of sandalwood oil compounds show the importance of conducting further research on sandalwood oil formation with consideration of the external and internal parameters.

\section{ACKNOWLEDGEMENTS}

Authors thank the Director and Group Coordinator Research of Institute of Wood Science and Technology, Bangalore-560003 for encouragement and support.

\section{REFERENCES}

Bajpai O, Pandey J \& Chaudhary LB (2016) Ethnomedicinal uses of tree species by Tharu tribes in the Himalayan Terai region of India. Research Journal of Medicinal Plant 10(1): 19-41.

Bisht SS \& Hemanthraj KPM (2014) Gas Chromatography-Mass Spectrometry (GC-MS) Profiling of Heartwood Oil Composition from 15 Years Old Sandalwood Trees. International Journal of Pharmacognosy and Phytochemical Research 6(2): 387-392. 
Brand J, Kimber P \& Streatfield J (2006) Preliminary analysis of Indian sandalwood (Santalum album L.) oil from a 14-year-old plantation at Kununurra. Western Australia. Sandalwood Research Newsletter 21: 1-3.

Brand JE, Fox JED, Pronk G \& Cornwell C (2007) Comparison of oil concentration and oil quality from Santalum spicatum and $S$. album plantations, 8-25 years old, with those from mature $S$. spicatum natural stands. Australian Forestry 70: 235.

Burdock G A \& Carabin I G (2008) Safety assessment of sandalwood oil (Santalum album L.). Food and Chemical Toxicology 46(2): 421-432.

Chaudhary LB, Kushwaha AK \& Bajpai O (2016) Santalum album L. In: Trees of Uttar Pradesh (Part 1). Bennett, Coleman \& Co. Ltd., Lucknow, India, pp. 296.

Doran JC, Thomson L, Brophy JJ, Goldsack B, Bulai P, Faka'osi T \& Mokoia T (2005) Variation in heartwood oil composition of young sandalwood trees in the south Pacific (Santalum yasi, S. album and F1 hybrids in Fiji, and S. yasi in Tonga and Niue). Sandalwood Research Newsletter 20: 3-7.

Fox JE (2000) Sandalwood: the royal tree. Biologist 47(1): 31-34.

Hansda R (2009) The outlook for non-wood forest products in Asia and the Pacific. In: Asia-Pacific Forestry Sector Outlook Study II Working Paper Series. p. 89.

Hettiarachchi DS (2008) Volatile oil content determination in the Australian sandalwood industry: Towards a standardised method. Sandalwood Research Newsletter 23: 1-4.

ISO (2002) International Organisation for Standardisation, $2^{\text {nd }}$ edition. ISO 3518.

Misra BB, Das SS \& Dey S (2013) Volatile profiling from heartwood of East Indian sandalwood tree. Journal of Pharmacy Research 7(4): 299-303.

Sensarma P (1989) Plants in the Indian Puranas. Naya Prokash.

Shankaranarayana KH, Ravikumar G, Rangaswamy CR \& Theagrajan KS (1998) On sandalwood HESP and ESPO oils from heartwood of sandal (sandal \& its products). Australian Centre for International Agricultural Research Proceedings 84: 89-92.

Subasinghe SMCUP (2013) Sandalwood research: a global perspective. Journal of Tropical Forestry and Environment 3(1): 1-8.

Verghese J, Sunny TP \& Balakrishnan KV (1990) (+)- $\alpha$-santalol and (-)- $\beta$-santalol (Z) concentration, a new quality determinant of East Indian sandalwood oil. Flavour and Fragrance Journal 5(4): 223-226.

Xiaojin L, Daping X, Zengjiang Y, Ningnan Z, Lijun Y (2011) Preliminary analysis of growth and oil composition from a 6-year-old sandal (Santalum album L.) plantation in Gaoyao, Guangdong, south China. Sandalwood Research Newsletter 26: 1-5. 